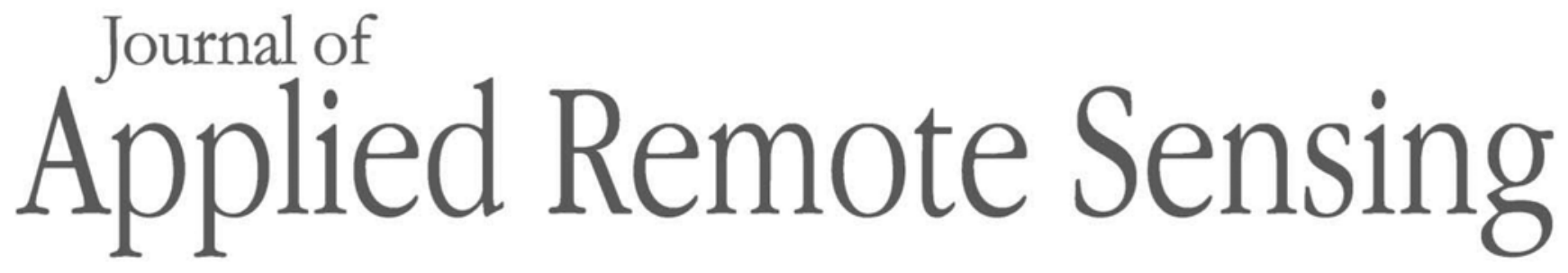

RemoteSensing.SPIEDigitalLibrary.org

\title{
Fundamental study for estimating rice-plant stem number using laser scanner measurements
}

\author{
Anh Thu Thi Phan \\ Atsushi Rikimaru \\ Yasuhiro Higuchi \\ Kazuyoshi Takahashi
}




\title{
Fundamental study for estimating rice-plant stem number using laser scanner measurements
}

\author{
Anh Thu Thi Phan,, Atsushi Rikimaru, ${ }^{\text {b }}$ Yasuhiro Higuchi, ${ }^{c}$ and \\ Kazuyoshi Takahashi ${ }^{\mathbf{b}, *}$

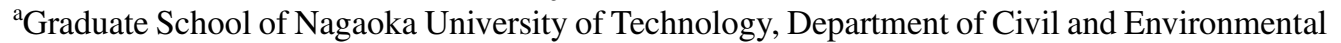 \\ Engineering, Nagaoka, Niigata, Japan \\ ${ }^{b}$ Nagaoka University of Technology, Nagaoka, Niigata, Japan \\ ${ }^{c}$ Niigata Agricultural Research Institute, Nagaoka, Niigata, Japan
}

\begin{abstract}
The number of rice-plant stems $(S)$, directly affecting the competition among rice plants and contributing to rice yield, is estimated from laser data. The laser data were normalized to eliminate the increasing plant height effect. Relative spatial volume $\left(r V_{s}^{\text {laser }}\right)$ was derived and scaled as an exponential function of $S$. A relationship between $r V_{s}^{\text {laser }}$ and $S$ is confirmed in two growing seasons (2014 and 2016, separately obtained by two different laser scanners). The scaling and exponent factors $(\beta$ and $\alpha$ ) depended on the planting geometry, planting density, and bottom position of the rice plants $\left(D^{\text {bottom }}\right)$ but were almost independent of the number of divided layers in the $r V_{s}^{\text {laser }}$ computation. From the estimated stem number using $D^{\text {bottom }}$ at the 80th percentile $\left(D^{80}\right)$, the maximum $S$ was obtained at $\sim 50$ days after transplanting. In both years, the relative error in the estimate was below 0.10 , and the bias was small. In the models with $D^{80}$ in $2014\left(M D_{2014}^{80}\right)$ and $D^{95}$ in $2016\left(M D_{2016}^{95}\right)$, the $\beta$ and $\alpha$ values were very similar. Using the $r V_{s}^{\text {laser }}$ measure, we can disregard the footprint characteristics and voxel size. The presented results support the proposed approach as a useful future method for estimating rice-plant stems. (C) The Authors. Published by SPIE under a Creative Commons Attribution 3.0 Unported License. Distribution or reproduction of this work in whole or in part requires full attribution of the original publication, including its DOI. [DOI: 10.1117/1.JRS.11.036012]
\end{abstract}

Keywords: relative spatial volume; rice growth parameters; precise agriculture.

Paper 170325 received Apr. 17, 2017; accepted for publication Jul. 27, 2017; published online Aug. 21, 2017.

\section{Introduction}

Crop growth monitoring has been the main focus of precise agricultural studies. Yields of rice, a staple food in Asian countries, directly affect the future security of rice-based foods. Rice growth has been monitored not only for food security but also for satisfying the demand for safe, affordable, high-quality rice. Many studies of grass food crops have inferred the crop growth from plant heights, stem numbers, the leaf area index, leaf color, fresh and dry weights, and crop growth rates. $^{1-5}$ By monitoring these crop growth parameters over time, crop growth can be controlled.

In Japan, rice growth is periodically measured by three main parameters: rice-plant height, rice-plant stem number, and rice leaf color. ${ }^{6}$ Both the rice-plant height and rice-plant stem number strongly influence the rice yield potential. In turn, the rice yield potential directly affects the panicle number. Together with the grain weight and spikelet per panicle, the rice-plant stem number determines the rice yield. ${ }^{7,8}$ The number of stems per plant hill depends on the nutrient status, ${ }^{9}$ rice variety, and planting density. Over past decades, the above-mentioned rice growth parameters were manually measured in the paddy field. Such measurements are monotonous, labor-intensive, and time-consuming; moreover, the result varies with the spatial distribution of samples and sample size. In some situations, especially in large fields, the sampled plants are difficult to evaluate. Modern remote-sensing techniques support the development of time- and labor-saving methods for monitoring crop growth parameters in agricultural production.

*Address all correspondence to: Kazuyoshi Takahashi, E-mail: ktakaha@nagaokaut.ac.jp 
Recently, laser scanning has become an effective technology in many research areas, such as photogrammetry, ${ }^{10,11}$ surveying, ${ }^{12}$ and structural damage detection. ${ }^{13,14}$ In agriculture, groundbased lasers have been popularly used in applications, such as biomass estimation ${ }^{15-20}$ and vertical plant-area density profiling. ${ }^{21,22}$ Ground-based lasers have demonstrated their usefulness in precise agriculture, as they collect large amounts of crop information within a short time. In fact, many studies of plant-height monitoring have reported the use of laser data. ${ }^{23-27}$ In our previous study, we introduced a method for estimating the heights of rice plants from laser data without requiring the ground-surface level. ${ }^{28}$ However, few studies have attempted the monitoring of rice-plant stem number. Therefore, a method for estimating rice-plant stem number is demanded for monitoring rice growth and predicting the rice yield potential.

The structures and functions of plants can be scaled as power functions of the measured size parameters. ${ }^{29,30}$ Applying this theory to light detection and ranging (LIDAR) data, researchers have estimated forest and individual tree parameters, such as the basal area and stem volume. In particular, the LIDAR tree height derived from LIDAR data has become a major variable in biomass estimation. For example, Drake et al. ${ }^{31}$ estimated the above-ground biomass from LIDAR data using an allometric equation based on stem diameter. In a pioneering study, Chen et al $^{32}$ calculated the volume from LIDAR data by the canopy-height model. Using this parameter, which they named the canopy geometric volume, they estimated the basal areas and stem volumes of individual trees. Hollaus et al. ${ }^{33}$ derived the volume from the terrain surface to the canopy from LIDAR data. They assumed a linear relationship between the LIDAR-derived canopy volume and the growing stock and stratified their metric into several canopy-height classes. By applying scaled power functions, other studies have estimated the forest parameters (tree height, stem volume, stem number, and basal area) from airborne laser scanning data. ${ }^{34-36}$ However, estimating agricultural crop production (and especially rice crop production) by this approach has been rarely reported. According to Norberg, ${ }^{37}$ the average plant volume can be scaled as a power function of population density. Therefore, we expect that rice-plant volume can be expressed as a scaled exponential function of the measured rice-plant stem number.

This study proposes a method for estimating rice-plant stem number from laser data. This fundamental methodology is expected to be aided by ground- or small unmanned aerial vehicle (UAV)-based laser scanner systems in the future. Our method relies on the relative spatial volume $(r V)$ metric, which is newly derived from laser point-cloud data. This metric is scaled by power functions to estimate the rice-plant stem number. The proposed method is evaluated on rice plants with different planting geometries. The field observation data were acquired by a line laser scanner during the rice-growing seasons of 2014 and 2016. The scanner was mounted vertically on a special rack for the observation of the rice canopy beneath it.

The remainder of this paper is structured as follows. Sections 2 and 3 describe the field and laser data acquisition and our proposed methodology, respectively. The plant stem number results are presented in Sec. 4 and discussed in Sec. 5. The study findings are summarized and concluded in Sec. 6.

\section{Data Acquisition}

\subsection{Field Data}

The test plots were established in a paddy of the Niigata Agricultural Research Institute in Niigata Prefecture, Japan. Before transplanting the rice-plant seedlings in early May, the paddy was treated with ground fertilizer $\left(3 \mathrm{~g} \mathrm{~N} / \mathrm{m}^{2}\right)$. In the 2014 growing season, each riceplant hill (containing four initial seedlings) was transplanted in five plots with various planting geometries. The planting density was varied as sparse $\left(11.2\right.$ plant hills $\left./ \mathrm{m}^{2}\right)$, moderate (15.1 plant hills $\left./ \mathrm{m}^{2}\right)$, and dense $\left(21.2\right.$ plant hills $\left./ \mathrm{m}^{2}\right)$. In the growing season of 2016 , the rice plants were transplanted in another paddy field with a single planting geometry (plot 2 in 2014; Table 1). The study was performed on Koshihikari rice, a popular rice variety in Japan.

According to the meteorological data recorded by the Automated Meteorological Data Acquisition System in Japan, the weather conditions differed between the 2014 and 2016 
Table 1 Rice planting densities and geometries during the growing seasons of 2014 and 2016.

\begin{tabular}{lccccc}
\hline \hline Plot & $\begin{array}{c}\text { Planting density } \\
\left.\text { (plant hills } / \mathrm{m}^{2}\right)\end{array}$ & $\begin{array}{c}\text { Planting } \\
\text { geometry }\end{array}$ & $\begin{array}{c}\text { Row orientation } \\
\text { relative to scanning plane }\end{array}$ & 2014 & Growing season \\
\hline 1 & 21.2 & $30 \mathrm{~cm} \times 16 \mathrm{~cm}$ & Perpendicular $(\perp)$ & $\checkmark$ & - \\
2 & 15.1 & $30 \mathrm{~cm} \times 22 \mathrm{~cm}$ & Perpendicular $(\perp)$ & $\checkmark$ & $\checkmark$ \\
3 & 11.2 & $30 \mathrm{~cm} \times 30 \mathrm{~cm}$ & - & $\checkmark$ & - \\
4 & 15.1 & $22 \mathrm{~cm} \times 30 \mathrm{~cm}$ & Parallel (II) & $\checkmark$ & - \\
5 & 21.2 & $16 \mathrm{~cm} \times 30 \mathrm{~cm}$ & Parallel (II) & $\checkmark$ & - \\
\hline \hline
\end{tabular}

Note: $\checkmark$ indicates the application of a planting geometry during the growing season.

growing seasons, but the average temperature was unchanged. ${ }^{38}$ Specifically, in late June to early July, when the rice-plant stems develop, the rainfall was higher in 2014 than in 2016, but the number of sunshine hours in 2014 was double that of 2016. Owing to the different soil and weather conditions, the rice growth parameters might vary between the two years. To validate the proposed method, we collected the growth parameters of the rice plants in a field investigation. The rice-plant height $(H)$ and rice-plant stem number $(S)$ were manually measured at irregular intervals during the rice-growing seasons of 2014 and 2016.

\subsection{Laser Data}

Seven observations were carried out during the vegetative stages of each growing season. The laser scanner was a SICK LMS 200 in 2014 and a UTM 30LX in 2016. Both scanners were mounted at $\sim 3 \mathrm{~m}$ above the ground surface (Fig. 1). The range measurement accuracies of SICK LMS 200 and UTM 30LX are $10 \mathrm{~mm}$ (at the typical range of $10 \mathrm{~m}$ ) and $30 \mathrm{~mm}$ at observing distances below $10 \mathrm{~m}$, respectively. In both scanners, the laser beam wavelength was $905 \mathrm{~nm}$, the angular resolution was $0.25 \mathrm{deg},{ }^{39,40}$ and the central scan angle was the nadir. Powered by a motor, the laser scanner moved along the slide rail to sample the rice canopy. UAV-based laser scanners with constant flight altitude and velocity operate by the same mechanism. Unfortunately, the shapes and sizes of the footprint differ between the laser scanners used in this study. Specifically, at an observed distance of $3 \mathrm{~m}$, the footprint of SICK LMS 200 is

(a)

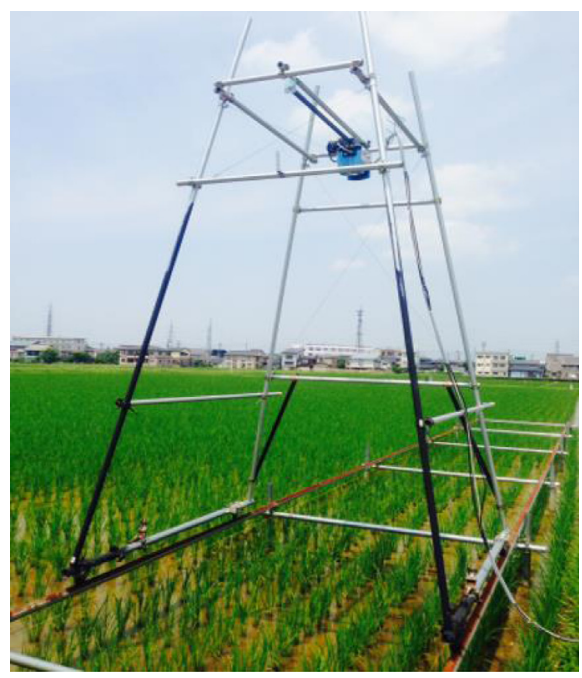

(b)

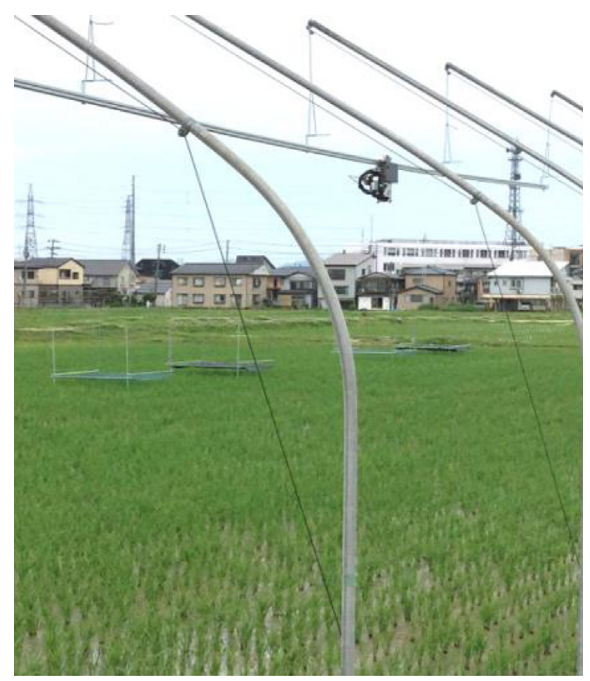

Fig. 1 Field observations were collected by laser scanners: (a) SICK LMS 200 and (b) UTM 30LX in 2014 and 2016, respectively. Both lasers were hung $\sim 3 \mathrm{~m}$ above the paddy field surface and could move along the rail under motorized power. 
a circle with an approximate diameter of $3 \mathrm{~cm}$, whereas that of UTM 30LX is rectangular and sized $0.8 \mathrm{~cm} \times 4 \mathrm{~cm}$. However, at the high density of the laser pulses, both laser scanners covered and returned the full information of the rice canopy. As the wind velocity remained below $2.5 \mathrm{~m} / \mathrm{s}$, high-quality laser data were recorded.

\section{Methodology}

This section introduces a dimensionless metric called the relative spatial volume $(r V)$, which is newly derived from laser point-cloud data. Theoretically, we assumed that laser data were collected under the ideal condition of nadir viewing and that the rice canopy was derivable from the laser data. Under these assumptions, we define the volume of space between the laser-derived rice canopy and the ground surface as the spatial volume $\left(V_{s}\right)$. As $V_{s}$ contains the rice plant, it is influenced by both the rice-plant height $(H)$ and the rice-plant stem number $(S)$. Additionally, $H$ increases over time. To eliminate the effect of $H$ on the time-series laser data, we normalize $V_{s}$ with $H$ to obtain the normalized spatial volume $\left(n V_{s}\right)$, which should change only with $S$. To eliminate the effect of voxel size, we also replace $n V_{s}$ with the relative spatial volume $\left(r V_{s}\right)$ obtained as the quotient of $n V_{s}$ and the maximum $n V_{s}$. In this way, the relationship between $r V_{s}$ and $S$ is maintained. According to our hypothesis, ${ }^{37} r V_{s}$ is expressed as a scaling exponent function of $S$; therefore, $S$ can be directly computed from the laser data.

To estimate $S$ directly from the laser data, $V_{s}$ is normalized by the relative vertical distance $(r D)$. The relationship between $S$ and the laser-derived relative spatial volume $\left(r V_{s}^{\text {laser }}\right)$ is then expressed in logarithmic form. From this expression, the allometric scaling factor and the exponent for estimating $S$ are computed by fitting the laser data by the least-squares method. Finally, we validate the accuracy of estimating the stem number from the laser data. The methodology is explained in detail in the following subsections.

\subsection{Basic Concepts of Estimating Rice-Plant Stem Number from Laser Data Under Ideal Conditions (Good Laser Data)}

\subsubsection{Basic hypothesis of laser-derived metrics}

In rice growth monitoring by laser measurements, the laser data must be properly fitted to the manually measured parameters of the rice plants. In this study, the laser-derived metrics appeared to be mainly related to $S$. After striking the rice canopy, the laser pulses emitted by the line laser scanner were immediately returned to the sensor. Therefore, the rice canopy surface could be reconstructed from the good quality laser data collected under the ideal condition of nadir viewing.

Spatial volume $\left(V_{s}\right)$ between the ground and laser-derived rice canopy surface. The spatial volume $V_{s}\left(\mathrm{~m}^{3}\right)$ is occupied by the rice plants and also by the empty space between the ground and the laser-derived rice canopy surface [Fig. 2(a)]. For visualization purposes, we describe $V_{s}$ as a voxel set [Figs. 2(b) and 2(c)]. Each voxel is a unit cubic volume of size $P_{\text {voxel }}$. The size $P_{\text {voxel }}$ must be sufficiently small to identify each part of the rice plant, such as the leaf and stem. Here, the voxel size was assumed as $\sim 1.0 \mathrm{~cm}^{3}$ under the ideal condition of the laser scanning points. $V_{S}$ can also be simply modeled from the measured rice-plant height $(H)$ and rice-plant stem number $(S)$ as a rectangular prism [Fig. 2(d)]. We imagine that rice-plant stems separate from each other and that each stem covers an individual area. Therefore, the surface area of this rectangular prism is an approximately area-proportional function of $S[f(S)]$. As a result, $V_{s}$ can be written as the product of rice-plant height $H(\mathrm{~m})$ and $f(S)\left(\mathrm{m}^{2}\right)$

$$
V_{s}=f(S) H .
$$

Normalized spatial volume $\left(n V_{s}\right)$. According to Eq. (1), $V_{s}$ is an increasing function of time, as both $S$ and $H$ increase over time. However, $H$ exerts a much clearer and stronger effect on $V_{s}$ than $S$. Whereas $S$ reached its maximum and then slightly decreased, $H$ increased 
(a)

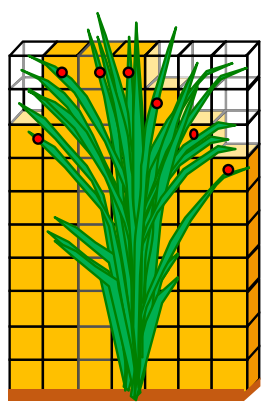

(c)

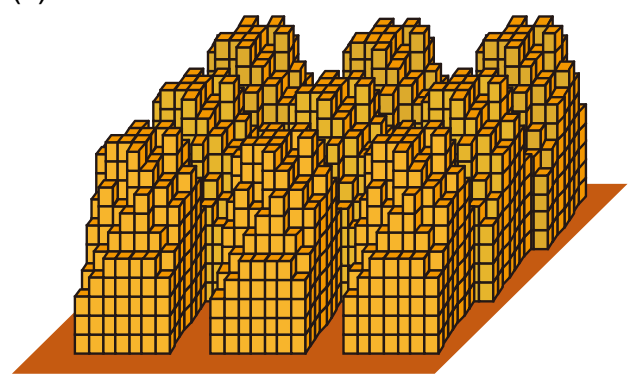

(b)

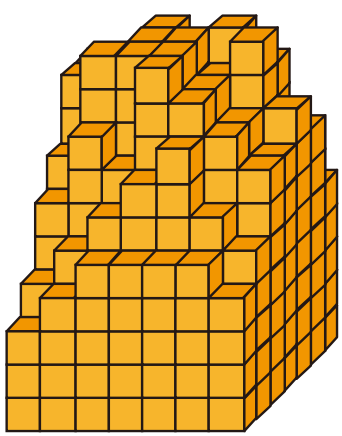

(d)

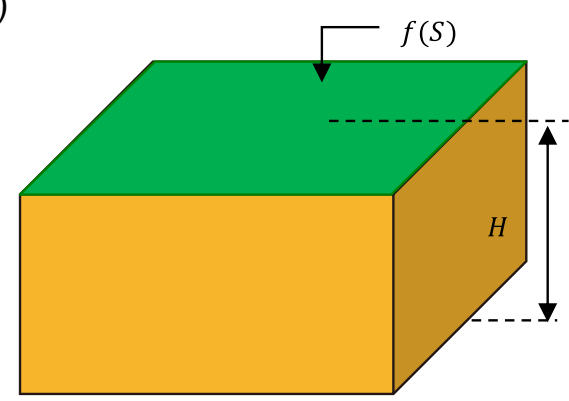

Fig. 2 Spatial volume $\left(V_{s}\right)$ between the ground and the rice canopy surface detected by the laser: (a) cross section of voxel representation of $V_{s}$, (b) voxel representations of a rice-plant hill, and (c) the target area, and the modeled $V_{s}$ expressed in terms of rice-plant height $H$ and the approximately area-proportional function of $S[f(S)](d)$.

throughout the growing period, so $V_{s}$ increased accordingly. Thus, to estimate $S$ from the timeseries laser data, we must remove the temporal effect of increasing $H$ from $V_{s}$. If $H$ were stable, any change in $V_{s}$ would be caused by $S$ alone. To this end, we normalize $V_{s}$ by $H$ at each given time $t$. The relationship between $V_{s}$ and its normalized version $\left(n V_{s}\right)$ is given as

$$
n V_{s}=\frac{V_{s}}{H}
$$

Therefore,

$$
n V_{s}=f(S)
$$

To derive the normalized spatial volume $\left(n V_{s}\right)$ from the laser scanning data, we first normalize the vertical distance $(D)$. Next, the scanning points (comprising the point cloud collected by the laser scanner) are divided into separate horizontal layers from the top to the bottom of the rice plants. The division is made at constant intervals $\Delta n D$ (where $n D$ denotes the normalized distance) [Fig. 3(a)]. Based on their normalized $D$ values, voxels are assigned to each layer [Fig. 3(b)]. Normalization alters the voxel size of a scanning point $\left(P_{\text {voxel }}\right)$ in the vertical dimension. Therefore, to compute the normalized spatial volume of layer $k\left(n V_{s}^{k}\right)$, we sum the scanning points in layers $1\left(x^{1}\right)$ to layer $k\left(x^{k}\right)$ obtained by the line laser scanner and scale the result by the voxel size after normalization $\left(n P_{\text {voxel }}\right)$ [Figs. 3(c) and 3(d)]

$$
n V_{s}^{k}=n P_{\text {voxel }} \sum_{i=1}^{k} x^{i}
$$

Then, $n V_{s}$ is computed as the sum of the normalized spatial volumes of all $n D$ layers ( $m$ layers) 

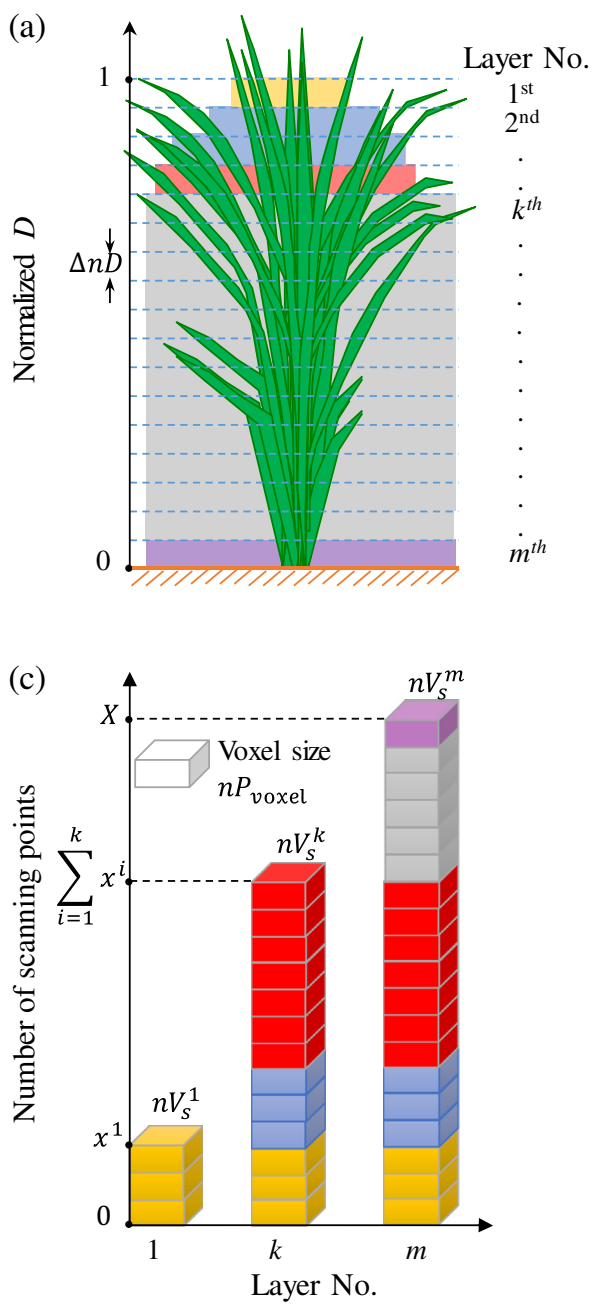

(b)

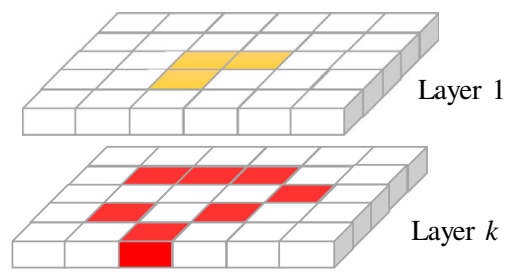

Voxels belong to layer 1

Voxels belong to layer $i(1<i<k)$

Voxels belong to layer $k$

(d)

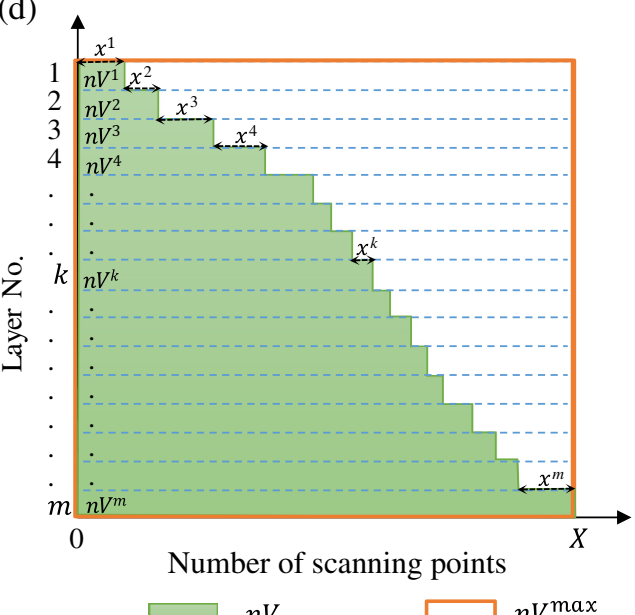

Fig. 3 Calculation of $n V_{s}$ from laser scanning data. (a) Top and bottom (close to the ground surface) positions of the rice plant used for normalizing $D$. The corresponding laser data are then divided into $m$ layers for the $n V_{s}$ computation. (b) Volumes (in voxels) of scanning points corresponding to each layer. $X$ is the total number of scanning points in the target area and $x^{i}$ is the number of scanning points in layer $i$. (c) Computation of $n V^{k}$ from the scanning points and (d) relationship between $n V$ and $n V^{\max }$.

$$
n V_{s}=n P_{\text {voxel }} \sum_{k=1}^{m} \sum_{i=1}^{\mathrm{k}} x^{i}
$$

Relative spatial volume $\left(r V_{s}\right)$. The normalized spatial volume $n V_{s}$ depends on the voxel size of the scanning point after normalization [Eq. (5)]. To remove the influence of $n P_{\text {voxel }}$ on the $n V_{s}$ computation, we propose a metric called the relative spatial volume $\left(r V_{s}\right)$. Assuming that all scanning points belong to the first layer, we find the maximum $n V_{s}\left(n V_{s}^{\max }\right)$. The relative spatial volume is then calculated as the quotient of $n V_{s}$ and $n V_{s}^{\max }$ as follows. Note that $r V_{s}$ is independent of $n P_{\text {voxel }}$

$$
r V_{s}=\frac{n V_{s}}{n V_{s}^{\max }}
$$

\subsubsection{Relationship between laser-derived metrics and rice-plant stem number}

Norberg ${ }^{37}$ demonstrated that the average plant volume can be scaled as a power function of the measured plant population density. Similarly, we hypothesize that $n V_{s}$ can be expressed as 
a scaling exponential function of $S$. In other words, $f(S)$ can be expressed as an approximate area-scaling factor $A\left(\mathrm{~m}^{2}\right)$ and an allometric exponent $\alpha(\alpha>0)$ [Eq. (3)]. Equation (6) can then be rewritten as

$$
r V_{s}=\frac{A}{n V_{s}^{\max }} S^{\alpha}
$$

As $n V_{s}^{\max }$ is constant in each target area, the above equation can be simplified by defining a dimensionless allometric scaling factor $\beta$ as follows:

$$
r V_{s}=\beta S^{\alpha} .
$$

For a specific rice variety, planting direction, and planting density, the allometric scaling $\beta$ and exponent $\alpha$ can be presumed to be unchanged over the study period. Under ideal conditions, $S$ can be directly computed from the laser data as follows:

$$
S=\left(\frac{r V_{s}}{\beta}\right)^{\frac{1}{\alpha}}
$$

\subsection{Conceptual Application Using the Observed Laser Data}

\subsubsection{Data extraction}

To ignore the effects of incident angle in this study, a small target area was located inside each plot. The targeted data were identified within inclination angles of $\pm 8 \mathrm{deg}$. Moreover, the five target areas in 2014 were limited to the same distance $(60 \mathrm{~cm}$ in the scanner moving direction), and both target areas in 2016 were narrowed to $\sim 100 \mathrm{~cm}$ along the rail. In our previous study, we computed $D$ of the scanning points by multiplying the observed range data by the cosine of the corresponding inclination angle. ${ }^{28}$ Here, $D$ denotes the position of the laser pulse on the rice canopy above the ground surface. Of course, the range of $D$ depends on the observation date because $H$ increases over time.

\subsubsection{Computation of relative spatial volume from the observed laser data}

As mentioned above, before deriving $n V_{s}$ from the observed laser data $\left(n V_{s}^{\text {laser }}\right)$, we normalize $D$ for each target area. Here, we assume that scanning angle effects can be ignored. As reported in our previous study, ${ }^{28}$ the relative vertical distance $(r D)$, computed directly from the laser data without considering the ground-surface level, was related to $H$ and was insignificantly affected by the planting density. Therefore, under the practical scenario of this study, we normalize $D$ not by $H$ but by the respective $r D$ s derived from the laser data at each observation time. For this purpose, the tops and bottoms of the rice plants were identified directly from the observed laser data. Phan et al. ${ }^{28}$ identified the top of the rice plant $\left(D^{\text {top }}\right)$ as the first percentile height. To avoid the effects of scanning points located on or just above the ground surface, we define the bottom of the rice plant $\left(D^{\text {bottom }}\right)$ by three rice bottom positions at the 70th, 80th, and 95th percentile heights $\left(D^{70}, D^{80}\right.$, and $D^{95}$, respectively). The normalized $D s(n D s)$ of the scanning points range from 0 (close to the bottom) to 1 (close to the top of the rice plant). Unfortunately, the collected data may contain error points caused by airborne particles or unexpected objects intercepting the transmission direction of the laser pulses. When identifying the top and bottom of the rice plant, these outliers were identified and eliminated by setting the valid range of $D$. Here, the valid $D$ range was identified from the measured plant height and the installation height of the laser scanner. To ensure a stable number of normalized scanning points, we set the $n D$ values of scanning points above the top position and below the bottom position as 1 and 0 , respectively.

If all laser scanning points $(X)$ belonged to the first layer, the normalized spatial volume would be maximized (i. e., $n V_{s}^{\max }$ ). To ensure a constant $n V_{s}^{\max }$, we counted all scanning points in all $n D$ layers ( $m$ layers) in the $n V_{s}^{\max }$ computation as follows: 


$$
n V_{s}^{\max }=n P_{\text {voxel }} m X
$$

The $n V_{s}^{\text {laser }}$ is then computed directly from $n D$ by summing the normalized spatial volumes of the $n D$ layers. To avoid the effect of scanning points on or just above the ground surface, we removed the last layer before computing $n V_{s}^{\text {laser }}$

$$
n V_{s}^{\text {laser }}=n P_{\text {voxel }} \sum_{k=1}^{m-1} \sum_{i=1}^{\mathrm{k}} x^{i}
$$

To remove $n P_{\text {voxel }}$, we then divided $n V_{s}^{\text {laser }}$ by $n V_{s}^{\max }$. This calculation gives the relative spatial volume from the observed laser data $\left(r V_{s}^{\text {laser }}\right)$. From Eqs. (10) and (11), we finally computed $r V_{s}^{\text {laser }}$ as follows:

$$
r V_{s}^{\text {laser }}=\frac{1}{m N} \sum_{k=1}^{m-1} \sum_{i=1}^{k} x^{i}
$$

As evident in the above equation, $r V_{s}^{\text {laser }}$ depends on the number of scanning points in each layer; consequently, $r V_{s}^{\text {laser }}$ depends on the value of $n D$ and the number of layers. Especially, the number of divided layers $(m)$ affects the histogram shape of $n D$. If $m$ is excessively small, the histogram distribution is lost; conversely, a too large $m$ unnecessarily increases the number of divided layers. Thus, we should investigate a suitable layer number in the $r V_{s}^{\text {laser }}$ calculation. In this study, the maximum rice-plant height was below $1.0 \mathrm{~m}$ during the target period. The voxel size in the vertical direction, which depends on the accuracies of the range measurements, was assumed as $1 \mathrm{~cm}$, so the height was divided into 100 layers. We expected that the most suitable $m$ is $\sim 100$ layers or less. Hence, the value of $m$ in the $r V_{s}^{\text {laser }}$ computation was varied around 100 layers as $m=\{500,100,50,5\}$.

\subsection{Regression Analysis}

In the next stage of the analysis, we identify the allometric scaling factor and the exponent ( $\beta$ and $\alpha$ ). Given these parameters, the stem number can be determined. In logarithmic form, the relationship between the rice-plant stem number and $r V_{s}^{\text {laser }}$ [Eq. (9)] becomes

$$
\ln S=\frac{1}{\alpha} \ln r V_{s}^{\text {laser }}-\frac{1}{\alpha} \ln \beta .
$$

To determine $\beta$ and $\alpha$ in the above equation, we fitted the laser data by the least-squares method. Finally, the accuracy of estimating the stem number from laser data was validated by the root-mean-square error (RMSE), the relative error ( $r E$, computed as the RMSE divided by the mean), and the bias value in each test plot. The bias value was determined by forcing the slope of the regression line slope to 1.0.

\section{Results}

According to the manual measurement results, $H$ increased linearly over time in 2014, and the results were consistent among the five plots. $H$ increased more rapidly in 2016 than in 2014, but the mature crop height was similar in both years [Fig. 4(a)]. In contrast, $S$ clearly varied among the plots of various planting densities and growing seasons [Fig. 4(b)]. The stem number $(S)$ was higher in the 2014 than in the 2016 growing season, possibly reflecting soil condition effects and the influences of weather factors, such as rainfall and hours of sunlight. $S$ was maximized at $~ 50$ days after transplanting and varied with planting density and plot geometry in 2014.

Before computing $r V_{s}^{\text {laser }}$, the time-varying $H$ effect was removed from the laser data by normalizing $D$ with various $D^{\text {bottom }}$ s (Fig. 5). When $D^{\text {bottom }}$ was set just above the ground surface, the ground-surface effect was not eliminated completely. For example, in the first observation (with $D^{\text {bottom }}$ close to 0 ), the $n D$ s of scanning points close to the ground surface deviated 

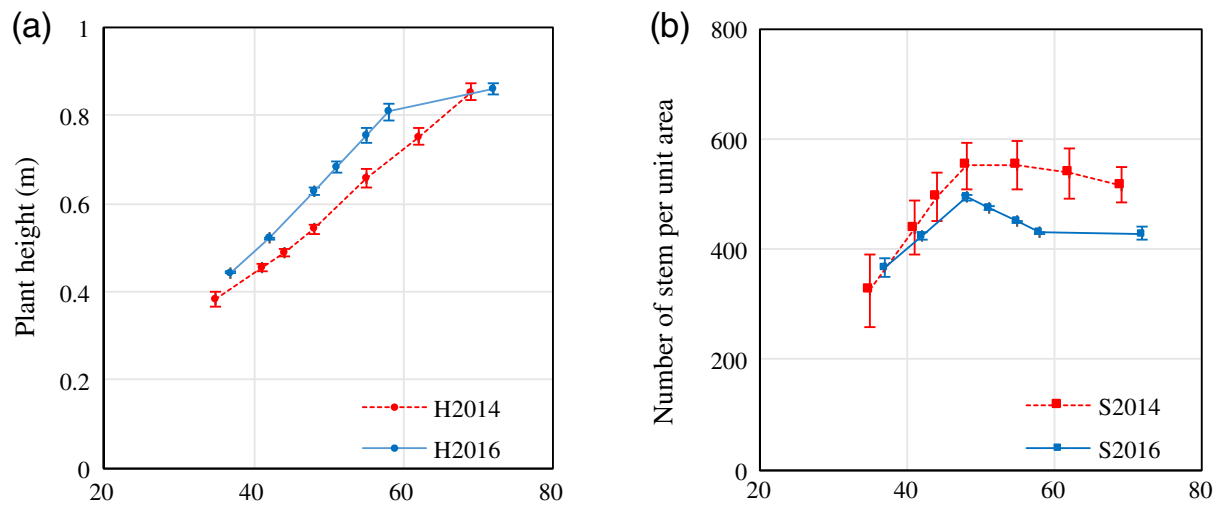

Days after transplanting (DAT)

Fig. 4 Manually measured physical parameters of rice plants: (a) average rice-plant height $(H)$ and (b) average rice-plant stem number $(S)$ in the two growing seasons (error bars are the standard deviations).

from 0 after normalizing the data [Figs. 5(b) and 5(f)]. On the other hand, when $D^{\text {bottom }}$ was set far above the ground surface, some of the rice-plant information was missed [Figs. 5(d) and 5 (h)]. In all cases, the $D^{80}$ setting achieved satisfactory $n D$ values because the scanning points close to the ground surface were removed with minimal loss of rice-plant information [Figs. 5(c) and $5(\mathrm{~g})]$. Next, we obtained the regression equations for estimating $S$ in each test plot with

(a)

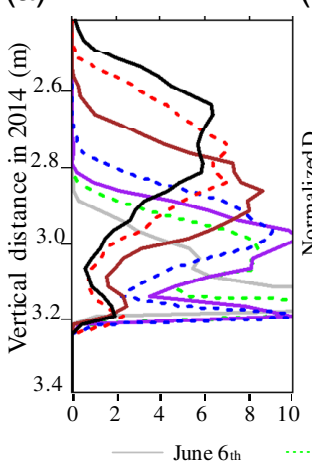

(b)

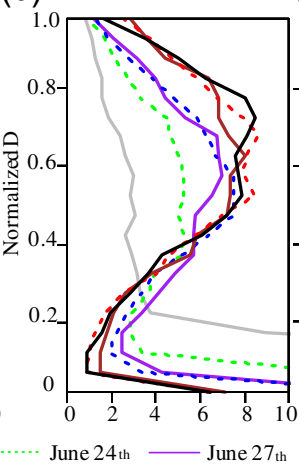

(c)

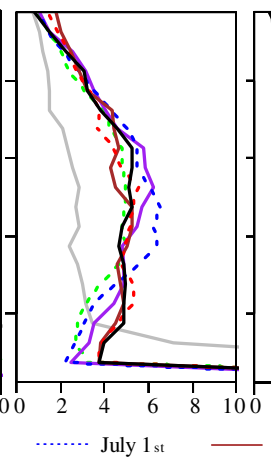

(d)

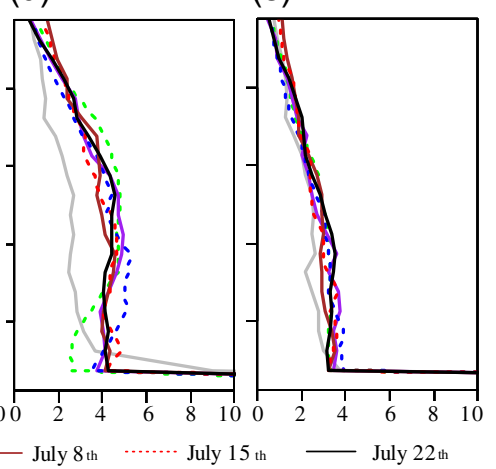

(f)

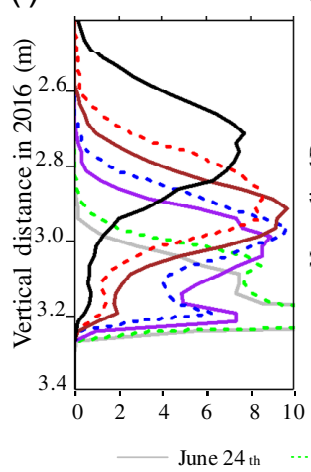

(g)

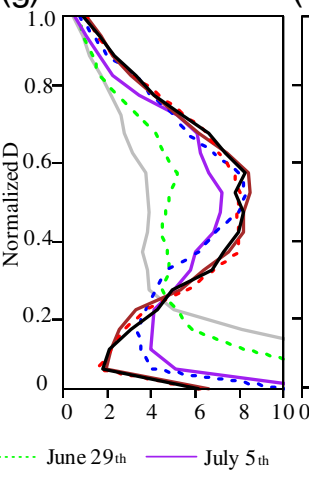

(h)

(i)

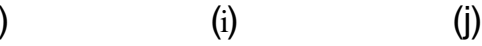

(j)

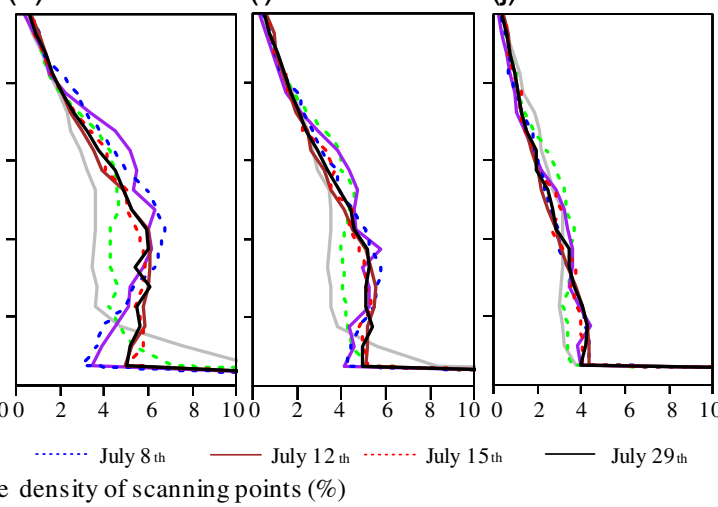

Fig. 5 Distributions of original and normalized data of seven observations collected at different times of the growing season in 2014 and 2016. The planting density was 15.1 plant hills $/ \mathrm{m}^{2}$, and the planting direction was perpendicular. Rows show the results from (a-d) 2014 to (e-h) 2016. Columns show the original data $(a, e)$ and the $n D$ values for different bottom positions of the rice plant: (b, f) $D^{95},(\mathrm{c}, \mathrm{g}) D^{80}$, and (d, h) $D^{70}$. 
various planting densities and geometries. In this study, $S$ was estimated directly from the laser data under various values of $\beta$ and $\alpha$ in the regression model, which relates $S$ to $r V_{s}^{\text {laser }}$. Owing to different structures of the rice-plant canopy surfaces, the $r V_{s}^{\text {laser }}$ values varied among the test plots. The allometric parameters also varied among the plots because the different planting geometries and densities led to different distributions of the laser scanning points. Additionally, the $n D$ values depended on the accuracy of computing $r D$ or on the identified $D^{\text {top }}$ and $D^{\text {bottom }}$. The distribution of $n D$ also influences $r V_{s}^{\text {laser }}$ because it decides the number of scanning points corresponding to each layer. Therefore, the allometric parameters computed from the observation data varied among the determined $D^{\text {bottom }}$ values and the test plots.

To illustrate our proposed approach, we calculated the allometric parameter values in the regression model from the observed laser data. The results are shown in Table 2. The results were validated on moderate density plots in the perpendicular planting direction (plot 2) (Table 3). Table 4 shows the effect of planting density and geometry on the precision of the estimated stem numbers. The validated parameters were unaffected by all values of $m$ above 10. In all cases, when $D^{\text {bottom }}$ was set at the 80th and 95 th percentile ranks $\left(M D^{80}\right.$ and $M D^{95}$, respectively), the $r E$ s were $\sim 0.10$ in both years (Table 3). However, the greatest stem number was clearly obtained at $M D^{80}$ (Figs. 6 and 7). In 2014, the $r E$ s of $M D^{80}$ were below 0.10 at all planting densities (Table 4). Moreover, the estimated $S$ closely approximated the manually measured $S$, especially in the growing season of 2016 (Fig. 8).

Table 2 Computed allometric parameters for the scaling exponential functions that predict the rice-plant stem number in moderate density plots.

\begin{tabular}{|c|c|c|c|c|c|c|c|c|}
\hline \multirow[b]{2}{*}{ Year } & \multirow{2}{*}{$\begin{array}{c}\text { Row } \\
\text { direction }\end{array}$} & \multirow{2}{*}{$\begin{array}{l}\text { Bottom } \\
\text { position }\end{array}$} & \multirow[b]{2}{*}{ Parameters } & \multicolumn{5}{|c|}{ Number of layers $(m)$} \\
\hline & & & & 500 & 100 & 50 & 10 & 5 \\
\hline \multirow[t]{12}{*}{2014} & ॥ & $D^{70}$ & $\ln \beta$ & 1.85 & 1.82 & 1.79 & 1.57 & 1.44 \\
\hline & & & $\alpha$ & 0.24 & 0.24 & 0.25 & 0.27 & 0.26 \\
\hline & & $D^{80}$ & $\ln \beta$ & 0.76 & 0.73 & 0.68 & 0.24 & -0.19 \\
\hline & & & $\alpha$ & 0.45 & 0.45 & 0.46 & 0.51 & 0.56 \\
\hline & & $D^{95}$ & $\ln \beta$ & -0.68 & -0.73 & -0.80 & -1.35 & -2.24 \\
\hline & & & $\alpha$ & 0.72 & 0.73 & 0.74 & 0.81 & 0.94 \\
\hline & $\perp$ & $D^{70}$ & $\ln \beta$ & -2.74 & -2.82 & -2.92 & -3.54 & -3.71 \\
\hline & & & $\alpha$ & 0.99 & 1.01 & 1.02 & 1.10 & 1.11 \\
\hline & & $D^{80}$ & $\ln \beta$ & -4.54 & -4.64 & -4.77 & -5.98 & -6.65 \\
\hline & & & $\alpha$ & 1.32 & 1.33 & 1.35 & 1.53 & 1.62 \\
\hline & & $D^{95}$ & $\ln \beta$ & -7.06 & -7.18 & -7.34 & -8.50 & -10.99 \\
\hline & & & $\alpha$ & 1.77 & 1.79 & 1.82 & 1.99 & 2.38 \\
\hline \multirow[t]{6}{*}{2016} & $\perp$ & $D^{70}$ & $\ln \beta$ & 0.18 & 0.13 & 0.08 & -0.27 & -0.43 \\
\hline & & & $\alpha$ & 0.51 & 0.51 & 0.52 & 0.56 & 0.56 \\
\hline & & $D^{80}$ & $\ln \beta$ & -3.00 & -3.08 & -3.18 & -3.89 & -4.53 \\
\hline & & & $\alpha$ & 1.06 & 1.07 & 1.08 & 1.18 & 1.27 \\
\hline & & $D^{95}$ & $\ln \beta$ & -4.40 & -4.50 & -4.62 & -5.71 & -7.09 \\
\hline & & & $\alpha$ & 1.33 & 1.35 & 1.37 & 1.53 & 1.74 \\
\hline
\end{tabular}


Table 3 Effect of layer number and bottom position of rice plant on the precision of the estimated stem number in a moderate density plot (plot 2) during the 2014 and 2016 growing seasons.

\begin{tabular}{|c|c|c|c|c|c|c|c|}
\hline \multirow[b]{2}{*}{ Year } & \multirow{2}{*}{$\begin{array}{l}\text { Bottom } \\
\text { position }\end{array}$} & \multirow{2}{*}{$\begin{array}{c}\text { Validated } \\
\text { parameters }\end{array}$} & \multicolumn{5}{|c|}{ Number of layers $(m)$} \\
\hline & & & 500 & 100 & 50 & 10 & 5 \\
\hline \multirow[t]{9}{*}{2014} & $D^{70}$ & $r E$ & 0.09 & 0.09 & 0.09 & 0.09 & 0.10 \\
\hline & & Bias & 2 & 2 & 2 & 2 & 2 \\
\hline & & RMSE & 41 & 41 & 41 & 41 & 44 \\
\hline & $D^{80}$ & $r E$ & 0.04 & 0.04 & 0.04 & 0.05 & 0.05 \\
\hline & & Bias & 0 & 0 & 0 & 0 & 0 \\
\hline & & RMSE & 20 & 20 & 20 & 21 & 22 \\
\hline & $D^{95}$ & $r E$ & 0.06 & 0.06 & 0.06 & 0.06 & 0.06 \\
\hline & & Bias & 1 & 1 & 1 & 1 & 1 \\
\hline & & RMSE & 28 & 28 & 28 & 27 & 24 \\
\hline \multirow[t]{9}{*}{2016} & $D^{70}$ & $r E$ & 0.08 & 0.08 & 0.08 & 0.08 & 0.09 \\
\hline & & Bias & 1 & 1 & 1 & 1 & 2 \\
\hline & & RMSE & 34 & 34 & 34 & 35 & 40 \\
\hline & $D^{80}$ & $r E$ & 0.04 & 0.04 & 0.04 & 0.04 & 0.04 \\
\hline & & Bias & 0 & 0 & 0 & 0 & 0 \\
\hline & & RMSE & 16 & 16 & 16 & 16 & 17 \\
\hline & $D^{95}$ & $r E$ & 0.10 & 0.10 & 0.10 & 0.10 & 0.10 \\
\hline & & Bias & 2 & 2 & 2 & 2 & 2 \\
\hline & & RMSE & 43 & 43 & 43 & 42 & 41 \\
\hline
\end{tabular}

\section{Discussion}

We have proposed an approach that estimates $S$ from laser scan data. The relationship between estimated rice-plant stem number and laser-derived relative volume is implied by the scaling factor $\beta$ and the allometric exponent $\alpha$ as shown in Table 2. The scaling factor $\beta$ reduced as $D^{\text {bottom }}$ approached the ground surface and increased in plots with parallel planting directions (Table 2). In contrast, the allometric exponent $\alpha$ reduced as $D^{\text {bottom }}$ increased from the ground surface and increased in plots with perpendicular planting direction. The values of $\beta$ and $\alpha$ were not significantly affected by the number of layers $(m)$, especially when $m$ exceeded 10 . In the moderately dense plot with perpendicular planting direction (plot 2), the allometric exponent $\alpha$ was similar in both growing seasons. Especially, in the models with $D^{\text {bottom }}$ at the 80th percentile rank of the 2014 growing season $\left(M D_{2014}^{80}\right)$ and at the 95th percentile rank in the 2016 growing season $\left(M D_{2016}^{95}\right), \alpha$ was identical when there were more than 10 divided $n D$ layers (Table 2). These results may be explained by the larger target area and the larger footprint of the laser sensor in 2016. In particular, owing to the large rectangular footprint of the UTM 30LX used in 2016, the laser pulses of UTM 30LX less easily reached the ground surface than those of SICK LMS 200. Under the same conditions of planting geometry and planting density, UTM 30LX recorded fewer scanning points at the ground surface than SICK LMS 200. Similarly, the top of the rice plant was less easily observed by the large footprint than by the small footprint. Consequently, the two sensors collected different distributions of the observation data. Specifically, the $D^{95}$ of the observation data was higher in 2016 than in 2014, whereas the $D^{1}$ of observation data was lower in 2016 than in 2014. However, the consistent 
Table 4 Effect of planting density and geometry on the precision of the estimated stem number in 2014 with $D^{\text {bottom }}=D^{80}$.

\begin{tabular}{|c|c|c|c|c|c|c|c|}
\hline \multirow[b]{2}{*}{ Planting density } & \multirow{2}{*}{$\begin{array}{c}\text { Row } \\
\text { direction }\end{array}$} & \multirow{2}{*}{$\begin{array}{l}\text { Validated } \\
\text { parameters }\end{array}$} & \multicolumn{5}{|c|}{ Number of layers $(m)$} \\
\hline & & & 500 & 100 & 50 & 10 & 5 \\
\hline \multirow[t]{3}{*}{21.2 (plant hills $/ \mathrm{m}^{2}$ ) } & $\perp$ & Bias & 0 & 0 & 0 & 0 & 0 \\
\hline & & RMSE & 19 & 19 & 19 & 19 & 20 \\
\hline & & $r E$ & 0.04 & 0.04 & 0.04 & 0.04 & 0.04 \\
\hline \multirow[t]{3}{*}{15.1 (plant hills $/ \mathrm{m}^{2}$ ) } & $\perp$ & Bias & 0 & 0 & 0 & 0 & 0 \\
\hline & & RMSE & 20 & 20 & 20 & 21 & 22 \\
\hline & & $r E$ & 0.04 & 0.04 & 0.04 & 0.05 & 0.05 \\
\hline \multirow[t]{3}{*}{11.2 (plant hills $\left./ \mathrm{m}^{2}\right)$} & - & Bias & 1 & 1 & 1 & 1 & 1 \\
\hline & & RMSE & 37 & 37 & 37 & 38 & 39 \\
\hline & & $r E$ & 0.08 & 0.08 & 0.08 & 0.09 & 0.09 \\
\hline \multirow[t]{3}{*}{15.1 (plant hills $/ \mathrm{m}^{2}$ ) } & $\|$ & Bias & 1 & 1 & 1 & 2 & 2 \\
\hline & & RMSE & 45 & 45 & 45 & 47 & 51 \\
\hline & & $r E$ & 0.09 & 0.09 & 0.09 & 0.09 & 0.10 \\
\hline \multirow[t]{3}{*}{21.2 (plant hills $/ \mathrm{m}^{2}$ ) } & $\|$ & Bias & 0 & 0 & 0 & 0 & 0 \\
\hline & & RMSE & 45 & 45 & 45 & 46 & 47 \\
\hline & & $r E$ & 0.09 & 0.09 & 0.09 & 0.09 & 0.09 \\
\hline
\end{tabular}

allometric exponent in both growing seasons confirms the dependability of the proposed hypothesis.

According to Eq. (12), $r V_{s}^{\text {laser }}$ depends on the number of scanning points in each layer $(x)$, which is decided by $m$. Setting $m$ too large is unnecessary, whereas setting $m$ too small provides insufficient information. Therefore, $m$ must be appropriately decided. However, as shown in Fig. 5, almost all of the $n D$ distributions are single modal, and the histogram curves are smooth, suggesting that the computed $r V_{s}^{\text {laser }}$ is independent of $m$. According to the results, the computed $r V_{s}^{\text {laser }}$ is stable for $m$ above 10. Moreover, the validated parameters were almost unchanged in this situation (Tables 3 and 4). When the number of divided layers is 10 or fewer, some specific information may be lost, increasing the computed RMSE (although the RMSE was insignificantly increased in this study). In general, the number of layers did not significantly affect the precision of the estimated stem number, but too few divided layers gave unsatisfactory results. When the number of layers exceeded 10 , the RMSE was acceptable $(r E \approx 0.10$; Table 3$)$. Therefore, the layer number $(m)$ should be $>10$ [Figs. 8(d)-8(f)]. The small achieved RMSEs inform that $r V_{s}^{\text {laser }}$ can be expressed as a scaling exponential function of $S$. The $r E s$ were also lower than 0.10 in the dense plots (Table 4). Additionally, the RMSE was influenced by the bottom position of the rice plant, the planting geometry, and the planting density (Table 3). The RMSE was minimized in the $M D^{80}$ setting (Table 3). For example, in the moderate density plot, the RMSE in this setting was 20 and $32 \mathrm{stem} \mathrm{m}^{-2}$ in 2014 and 2016, respectively. Although the $r E$ was always $\sim 0.10$ in models with $D^{80}\left(M D^{80}\right)$ and $D^{95}\left(M D^{95}\right)$, only $M D^{80}$ maximized the $S$ of the rice plants (Figs. 6 and 7). We consider that $D^{95}$ was too close to the ground surface, so it could not escape the ground-surface effects, whereas upper $D^{80}$ was too far above the ground surface to capture all of the plant information. Therefore, identifying the suitable position of the rice-plant bottom is important. In the present results, the appropriate bottom position of the rice plants was $D^{80}$. In this situation, the estimated rice-plant stem number strongly correlates with the laser-derived relative volume $\left(r V_{s}^{\text {laser }}\right)$. According to the $M D^{80}$ results, the correlation 


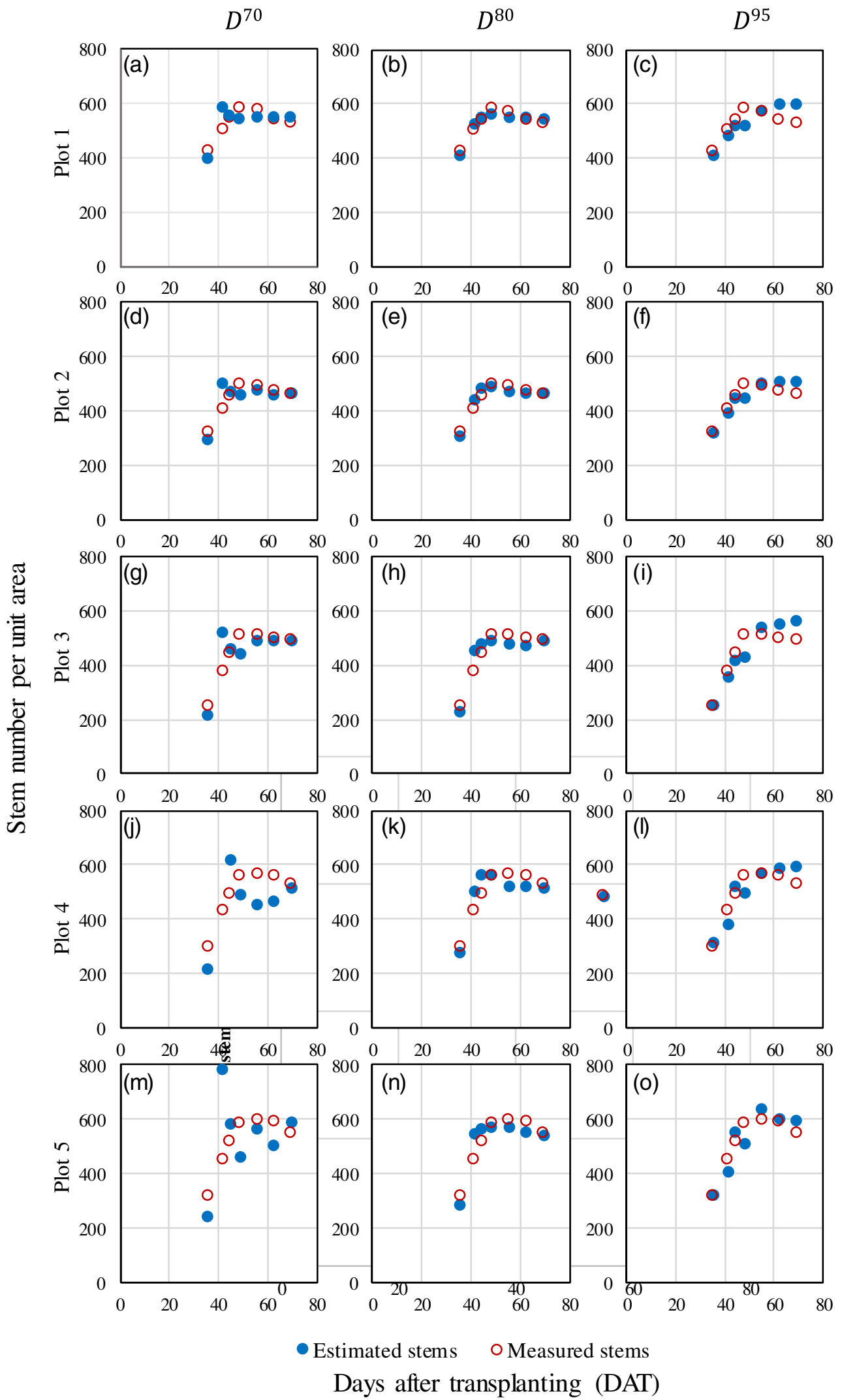

Fig. 6 Estimated rice-plant stem numbers during the growing season of 2014. Rows show the results from $(a-c)$ plot 1 , (d-f) plot 2, (g-i) plot 3, (j-l) plot 4 , and $(m-0)$ plot 5 . Columns show the results for different bottom positions of the rice plants: $(\mathrm{a}, \mathrm{d}, \mathrm{g}, \mathrm{j}, \mathrm{m}) D^{70},(\mathrm{~b}, \mathrm{e}, \mathrm{h}, \mathrm{k}, \mathrm{m}) D^{80}$, and $(\mathrm{c}, \mathrm{f}, \mathrm{i}, \mathrm{l}, \mathrm{o}) D^{95}$. 

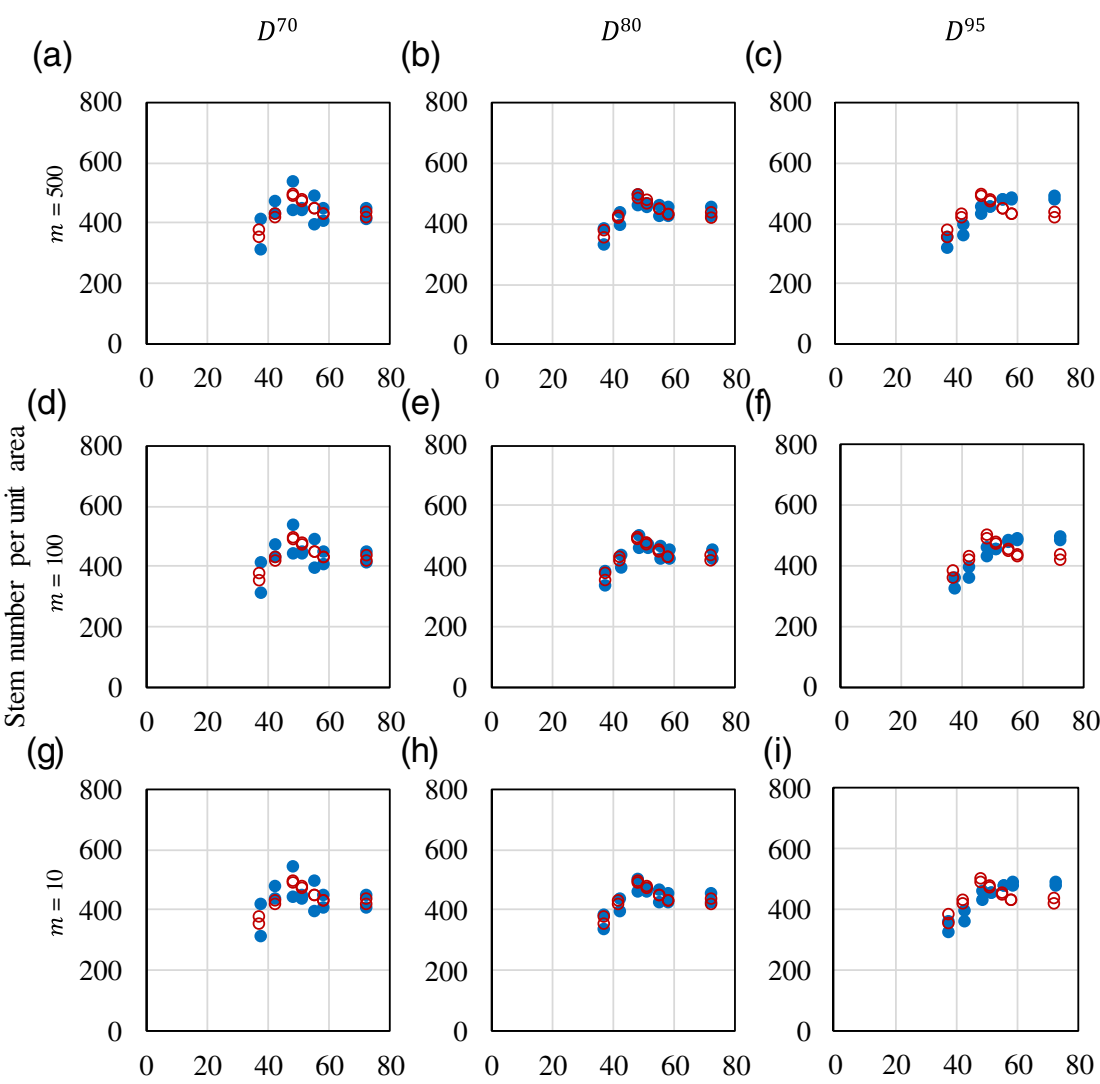

- Estimated stems o Measured stems

Days after transplanting (DAT)

Fig. 7 Estimated rice-plant stem numbers during the growing season of 2016. Rows show the results for different numbers of layers: (a-c) $m=500$, (d-f) $m=100$, and (g-i) $m=10$. Columns show the results for different bottom positions of the rice plants: $(\mathrm{a}, \mathrm{d}, \mathrm{g}) D^{70}$, (b, e, h) $D^{80}$, and (c, f, i) $D^{95}$.

coefficient $r$ ranged from 0.89 to 0.94 in 2014 and equaled 0.91 in 2016. Moreover, the RMSE exceeded the bias value in all cases of $M D^{80}$ and $M D^{95}$. In both years, the bias was $\sim 0$. The estimated and manually measured $S$ values were always consistent, even under dense planting conditions (Table 4), demonstrating the effectiveness of the proposed method (Fig. 8). However, a decisive conclusion requires more than three levels of planting density. The planting density effects should be thoroughly assessed in a future study.

In previous forest inventory studies, volume computations required the digital terrestrial model or digital elevation model as a reference surface. ${ }^{32-36}$ In contrast, this study computes the metric $r V_{s}^{\text {laser }}$ directly from the laser data without considering the ground-surface level. Moreover, a voxel-based representation of $V_{s}$ requires a suitable voxel size, which depends on the laser scanner, observed range, and study scale. ${ }^{41,42}$ In the proposed method, the whole scanning points need not be directly transferred into a continuous three-dimensional voxel grid. In other words, we can disregard the footprint size, footprint shape, and voxel size. The proposed method is expected to be compatible with various sensors for future monitoring of rice crops by UAV-based laser measurements.

To achieve accurate monitoring, the laser data in this study were collected in almost-nadir viewing. Therefore, the effect of scanning angle could be ignored. Moreover, the $n V_{s}^{\max }$ plays an important role in obtaining $r V_{s}^{\text {laser }}$. However, $n V_{s}^{\max }$ depends on the scanning point density and the observation distance between the target object and sensor, which affect the values of $X$ and $P_{\text {voxel }}$, respectively. The scanning points acquired by the scanner should be sufficiently dense and small to achieve the expected result. Additionally, the planting and environmental (e.g., wind) conditions might also affect the observation data. These effects were not eliminated in this study. 

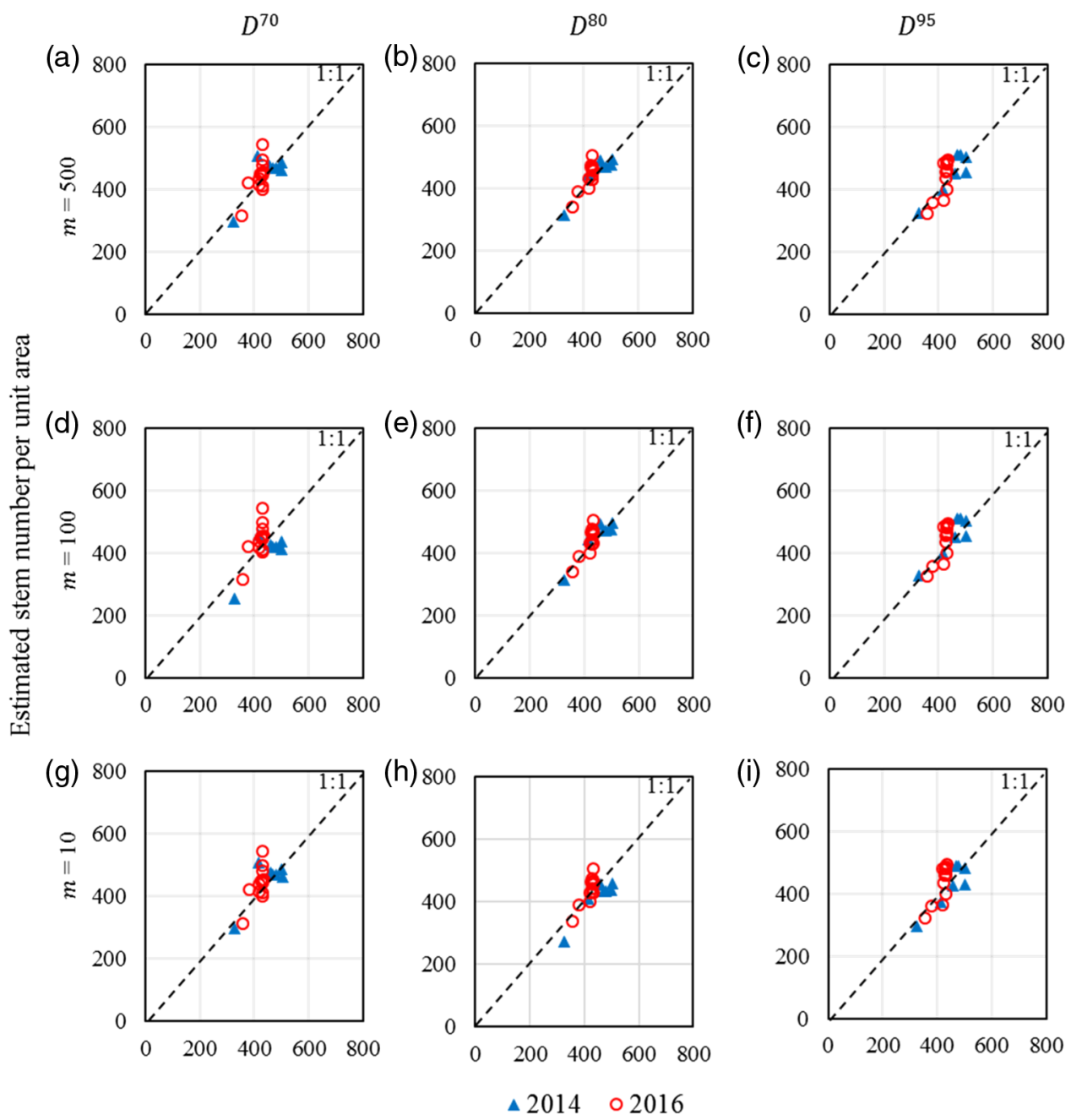

Manual measured stem number per unit area

Fig. 8 Estimated $S$ (with 100 divided layers) versus manually measured $S$ during the growing season of 2014 (red) and 2016 (blue). Rows show the results for different numbers of layers: (a-c) $m=500$, (d-f) $m=100$, and (g-i) $m=10$. Columns show the results for different bottom positions of the rice plants: $(\mathrm{a}, \mathrm{d}, \mathrm{g}) D^{70},(\mathrm{~b}, \mathrm{e}, \mathrm{h}) D^{80}$, and $(\mathrm{c}, \mathrm{f}, \mathrm{i}) D^{95}$.

Because the plant-rice stem number and uniformity of the rice canopy structure depended on the planting geometry, the allometric parameters were altered by the characteristics of the rice canopy surface. Moreover, the quality of laser data is compromised by environmental factors. In 2016, the wind velocity was below $2.5 \mathrm{~m} / \mathrm{s}$, and high-quality laser data were recorded. On the fifth observation in 2014, the rice leaves were lifted by strong winds, and the observation data were degraded by noise. In this situation, the noise scanning points could not be identified by setting the valid range of $D$. Although this study achieved favorable results under dense planting conditions, the above-mentioned limitations should be carefully considered in future study.

\section{Conclusion}

This study estimated the number of rice stems $S$, which directly affects rice-plant competition and contributes to rice yield, from laser scanner data. To this end, we derived the relative spatial volume $\left(r V_{s}^{\text {laser }}\right)$ from the laser data and presented it as an exponential function of $S$. The results confirmed the relationship between $r V_{s}^{\text {laser }}$ and $S$ and demonstrated that rice-plant stem number can be estimated directly from laser scanning data. 
The effect of rice-plant height in the laser data was removed by normalizing the data, and the ground surface was eliminated by removing the ground-surface scanning points. The allometric parameters were determined in both growing seasons, although different line laser scanning devices were applied in the two seasons. The parameters depend on the planting geometry, planting density, and $D^{\text {bottom }}$ but were almost independent of the number of layers. The layer number should be $>10(m>10)$. However, in the moderate density plot with perpendicular planting direction (plot 2), all cases clearly obtained the maximum $S$ from the estimated stem number with $r E$ values of $\sim 0.10$. Moreover, the values of $\beta$ and $\alpha$ of $M D_{2014}^{80}$ and $M D_{2016}^{95}$ were very similar, despite the different footprint sizes and shapes of the laser scanners. Therefore, using the $r V_{s}^{\text {laser }}$ metric, we need not consider the footprint shape or $P_{\text {voxel }}$. Moreover, the small bias value confirmed the good match between the estimated $S$ and manually measured $S$. By virtue of these promising results, the proposed approach is expected to be recommended for rice-plant stem estimation from data collected by different sensors.

The major limitation of this approach is the dependence of the allometric parameters on the planting conditions, including the density and geometry of the plantings. Moreover, the environmental effects were not completely removed from the laser data. In future work, the effects of planting geometry and environment should be considered in a refined version of the method.

\section{Acknowledgments}

This study was partially supported by Japan Society for the Promotion of Science KAKENHI Grant Nos. 23580361 and 26450362.

\section{References}

1. A. Dobermann and M. F. Pampolino, "Indirect leaf area index measurement as a tool for characterizing rice growth at the field scale," Commun. Soil Sci. Plant Anal. 26(9-10), 1507-1523 (1995).

2. T. Takai et al., "Rice yield potential is closely related to crop growth rate during late reproductive period," Field Crops Res. 96, 328-335 (2006).

3. M. Hasanuzzaman et al., "Plant growth pattern, tiller dynamics and dry matter accumulation of wetland rice (Oryza sativa L.) as influenced by application of different manures," Nat. Sci. 8(4), 1-10 (2010).

4. B. Singh et al., "Fixed-time adjustable dose site-specific fertilizer nitrogen management in transplanted irrigated rice (Oryza sativa L.) in South Asia," Field Crops Res. 126, 63-69 (2012).

5. J. Bendig et al., "Estimating biomass of barley using crop surface models (CSMs) derived from UAV-based RGB imaging," Remote Sens. 6, 10395-10412 (2014).

6. Y. Yamamoto, S. Kawaguchi, and W. Takahashi, "Application of developmental model for analysis of growth and development of rice transplanted in different plant numbers per hill," Jpn. J. Crop Sci. 63(2), 208-214 (1994).

7. F. Wang, F. M. Cheng, and G. P. Zhang, "Difference in grain yield and quality among tillers in rice genotypes differing in tillering capacity," Rice Sci. 14, 135-140 (2007).

8. M. A. Badshah et al., "Yield and tillering response of super hybrid rice Liangyoupeijiu to tillage and establishment methods," Crop J. 2(1), 79-86 (2014).

9. IRRI, "Seeding rates and plant populations," http://www.knowledgebank.irri.org/ ericeproduction/II.6_Seedling_and_plant_rate.htm (29 March 2015).

10. A. Wehra and U. Lohrb, "Airborne laser scanning-an introduction and overview," J. Photogramm. Remote Sens. 54(2-3), 68-82 (1999).

11. E. P. Baltsavias, "A comparison between photogrammetry and laser scanning," J. Photogramm. Remote Sens. 54(2-3), 83-94 (1999).

12. E. J. Huising and L. M. Gomes Pereira, "Errors and accuracy estimates of laser data acquired by various laser scanning systems for topographic applications," J. Photogramm. Remote Sens. 53(5), 245-261 (1998). 
13. I. Lubowiecka et al., "Historic bridge modelling using laser scanning, ground penetrating radar and finite element methods in the context of structural dynamics," Eng. Struct. 31(11), 2667-2676 (2009).

14. J. Armesto-González et al., "Terrestrial laser scanning intensity data applied to damage detection for historical buildings," J. Archaeol. Sci. 37(12), 3037-3047 (2010).

15. N. Tilly et al., "Precise plant height monitoring and biomass estimation with terrestrial laser scanning in paddy rice," ISPRS Ann. Photogramm. Remote Sens. Spat. Inf. Sci. II-5/W2, 295-300 (2013).

16. N. Tilly et al., "Multitemporal crop surface models: accurate plant height measurement and biomass estimation with terrestrial laser scanning in paddy rice," J. Appl. Remote Sens. 8, 083671 (2014).

17. D. Ehlert, H. J. Horn, and R. Adamek, "Measuring crop biomass density by laser triangulation," Comput. Electron. Agric. 61(2), 117-125 (2008).

18. D. Ehlert, H. J. Horn, and R. Adamek, "Suitability of a laser rangefinder to characterize winter wheat," Precis. Agric. 11, 650-663 (2010).

19. D. Ehlert and M. Heisig, "Sources of angle-dependent errors in terrestrial laser scannerbased crop stand measurement," Comput. Electron. Agric. 93, 10-16 (2013).

20. J. Bendig et al., "Estimating biomass of barley using crop surface models (CSMs) derived from UAV-based RGB imaging," Remote Sens. 6, 10395-10412 (2014).

21. F. Hosoi and K. Omasa, "Estimation of vertical plant area density profiles in a rice canopy at different growth stages by high-resolution portable scanning LIDAR with a lightweight mirror," ISPRS J. Photogramm. Remote Sens. 74, 11-19 (2012).

22. F. Hosoi and K. Omasa, "Estimating vertical plant area density profile and growth parameters of a wheat canopy at different growth stages using three-dimensional portable lidar imaging," ISPRS J. Photogramm. Remote Sens. 64, 151-158 (2009).

23. J. Lumme et al., "Terrestrial laser scanning of agricultural crops," Int. Arch. Photogramm. Remote Sens. Spat. Inf. Sci. XXXVII. B5, 563-566 (2008).

24. D. Hoffmeister et al., "High resolution Crop Surface Models (CSM) and Crop Volume Models (CVM) on field level by terrestrial laser scanning," Proc. SPIE 7840, 78400E (2010).

25. L. Zhang and T. E. Grift, "A LIDAR-based crop height measurement system for Miscanthus giganteus," Comput. Electron. Agric. 85, 70-76 (2012).

26. Y. Kaizu, J. M. Choi, and T. H. Kang, "Grass height and yield estimation using a threedimensional laser scanner," Environ. Control Biol. 50(1), 41-51 (2012).

27. N. Tilly et al., "Evaluation of terrestrial laser scanning for rice growth monitoring," Int. Arch. Photogramm. Remote Sens. Spat. Inf. Sci. XXXIX-B7, 351-356 (2012).

28. A. T. T. Phan et al., "Method for estimating rice plant height without ground surface detection using laser scanner measurement," J. Appl. Remote Sens. 10(4), 046018 (2016).

29. G. B. West, J. H. Brown, and B. J. Enquist, "A general model for the structure and allometry of plant vascular systems," Nature 400, 664-667 (1999).

30. B. J. Enquist, "Universal scaling in tree and vascular plant allometry: toward a general quantitative theory linking plant form and function from cells to ecosystems," Tree Physiol. 22(15-16), 1045-1064 (2002).

31. J. B. Drake et al., "Estimation of tropical forest structural characteristics using largefootprint lidar," Remote Sens. Environ. 79(2-3), 305-319 (2002).

32. Q. Chen et al., "Estimating basal area and stem volume for individual trees from lidar data," Photogramm. Eng. Remote Sens. 73(12), 1355-1365 (2007).

33. M. Hollaus et al., "Growing stock estimation for alpine forests in Austria: a robust lidarbased approach," Can. J. For. Res. 39, 1387-1400 (2009).

34. S. G. Tesfamichael, J. A. N. van Aardt, and F. Ahmed, "Estimating plot-level tree height and volume of Eucalyptus grandis plantations using small-footprint, discrete return lidar data," Prog. Phys. Geogr. 34(4), 515-540 (2010).

35. C. Straub and B. Koch, "Estimating single tree stem volume of Pinus sylvestris using airborne laser scanner and multispectral line scanner data," Remote Sens. 3, 929-944 (2011). 
36. E. Lindberg and M. Hollaus, "Comparison of methods for estimation of stem volume, stem number and basal area from airborne laser scanning data in a hemi-boreal forest," Remote Sens. 4, 1004-1023 (2012).

37. R. A. Norberg, "Theory of growth geometry of plants and self-thinning of plant populations: geometric similarity, elastic similarity, and different growth modes of plant parts," Am. Nat. 131(2), 220-256 (1988).

38. Japan Meteorological Agency, "Meteorological data," http://www.data.jma.go.jp/obd/stats/ etrn/index.php (29 February 2017).

39. SICK AG, "LMS200/211/221/291 laser measurement systems," http://sicktoolbox. sourceforge.net/docs/sick-lms-technical-description.pdf (20 March 2014).

40. Hokuyo, "Technical document," https://www.hokuyo-aut.jp/02sensor/07scanner/utm_30lx. html (20 January 2017).

41. F. Hosoi and K. Omasa, "Voxel-based 3-D modeling of individual trees for estimating leaf area density using high-resolution portable scanning Lidar," IEEE Trans. Geosci. Remote Sens. 44(12), 3610-3618 (2006).

42. Y. Song et al., "Voxel-based estimation of plant area density from airborne laser scanner data," Int. Arch. Photogramm. Remote Sens. Spatial Inf. Sci. XXXVIII-5/W12, 209-212 (2011).

Biographies for the authors are not available. 